\title{
Celebrating the 50th Anniversary of the Journal, Behavior Genetics
}

\author{
John K. Hewitt ${ }^{1}$ \\ Published online: 21 November 2019 \\ (c) Springer Science+Business Media, LLC, part of Springer Nature 2019
}

This month, January 2020, marks the 50th anniversary of the founding of the journal Behavior Genetics in 1970 by John DeFries and Steven Vandenberg, both then Faculty Fellows at the newly established Institute for Behavioral Genetics, University of Colorado Boulder. On the first page of the new journal they expressed their view that 'behavior genetics is simply the intersection between genetics and the behavioral science' but hoped that, '[the journal, Behavior Genetics,] will provide a medium for those persons especially interested in the problems which cut across many disciplines.' They also, perhaps with an abundance of caution, allowed that 'natural selection shall pass final judgment upon the adaptedness of our new recombinant.' (Vandenberg and DeFries 1970).

Fifty years later, it seems that natural selection has passed at least an interim judgement. Over 7000 papers and abstracts on animal and human behavior genetics have been published in the journal, with some papers cited over a thousand times each. A conservative journal wide h-index, calculated by the 'Web of Science', stands at 105; that is, at least 105 papers published in the journal have been cited at least 105 times. In recent years, there have been over 100,000 electronic downloads from the journal annually. The journal has survived through several changes of publisher, and is currently published by the powerhouse Springer Nature group. Since 1974, the journal has been the official publication of the Behavior Genetics Association and the leading specialist journal its field.

To celebrate this scientific publishing jubilee, we have assembled a special on-line only issue in addition to the normal publication. It can be found at www.springer.com/10519 starting in January 2020. In it we reprint the inaugural editorial from the first issue of Behavior Genetics, 1970, volume 1 , issue 1 , pages $1-2$. Together with that editorial,

John K. Hewitt

john.hewitt@colorado.edu

1 Institute for Behavioral Genetics, University of Colorado Boulder, Boulder, USA we include five papers from among the most highly cited articles published in the journal, illustrating some of the breadth, depth, and influence of the journal.

The first of these is 'Haseman and Elston (1972)', a paper that focused on a method for linkage studies for quantitative traits. The paper provided a methodological basis for detection of QTLs (quantitative trait loci) and introduced the centrally important concept of IBD (Identity By Descent) to the behavior genetics readership. Although now largely superseded by genome wide association studies (GWAS), this paper, written half a century ago, is still considered groundbreaking. It is also a densely written methodological paper, reportedly described by a leading contemporary quantitative geneticist (Alan Robertson) as 'the most obscure paper that he has had the misfortune to read for a long time'. This anecdote was revealed in an interesting and entertaining historical note on the paper, and the reaction it provoked, published to mark its fortieth anniversary (DeFries 2010).

Next is a review and empirical study of genetic and environmental influences on BMI (Body Mass Index) from twin and family studies (Maes et al. 1997). This highly cited paper summarized and modelled data from over 25,000 twin pairs and 50,000 biological and adoptive family members, and provides a benchmark for our understanding of individual differences in BMI as substantially genetically influenced. For comprehensiveness, thoroughness, and rigor this paper stands out as a classic in the field of twin and family studies. But is BMI a behavior? Though it is clearly an anthropometric index based on physical measurements, editors of Behavior Genetics have consistently considered BMI and similar phenotypes to be sufficiently mediated by behavior to fall within the journal's purview. Had we not, we would have passed up some of the more impactful papers we have published.

The third paper reprinted here is the classic review of the genetics of personality published by Bouchard and Loehlin (2001). This paper can be read to learn what behavior geneticists know about genes, evolution, and personality, at least to that date; and the empirical findings reviewed, rather than theoretical speculation, stand now as much as 
then. The paper can also be read with advantage as a review of the behavior genetic approach to pretty much any domain of individual differences, setting out the kinds of questions about both genetic and environmental influences that are of interest, anchoring the review of human behavior in its evolutionary and comparative psychological context, and making the argument that, essentially, individual differences in behavior can be studied in a similar way to individual differences in any other biological phenotype.

The fourth paper (DeFries and Fulker 1985) was the original presentation of what has become widely known as 'DeFries-Fulker regression'. This is a conceptually appealing analytic approach to testing for genetic influence, and estimating heritability and components of environmental influence, based on the concept of regression to the mean for correlated observations, such as those from pairs of twins or siblings. A large part of its appeal is that it can be applied, with appropriate modifications, to selected samples, such as individuals with reading disability, or to unselected samples alike. This provides not only a straightforward and flexible analytic strategy, but also an approach to addressing the question of whether extreme phenotypes and normal variation have similar or different etiologies. The method has been used in hundreds of empirical studies and is still widely used today, more than 30 years since it was first proposed.

Our final paper in this commemorative issue reflects the fact that Behavior Genetics has always welcomed and published papers on animal as well as human behavior genetics, primarily on the model organisms most widely in use-mice, rats, and fruit flies-but also on fish, whales, chickens, dogs, pigs, monkeys, apes and other animals. The paper reprinted here (Jallon 1984) is a review by the eminent French biologist, Jean-Marc Jallon, of the chemical signals involved in courtship and mating in the fruit fly, along with their genetic variation. This paper was in fact Prof. Jallon's most highly cited publication, eclipsing even a 1997 paper in Science reporting on the consequences of feminizing the male pheromones in Drosophila melanogaster (through manipulation of gene expression), including the elicitation of male homosexual courtship from other males (Ferveur et al. 1997). Sadly, Prof. Jallon, passed away recently (September 2019), after a distinguished and prominent career in the biological sciences.

Together, the collection of papers in this jubilee issue illustrates some of the scope and long range impact of the journal Behavior Genetics. The journal that was conceived and born, somewhat tentatively, during the early years of an emerging interdisciplinary field, not only survives but thrives as a venue for rigorous, peer reviewed, behavior genetic science.

\section{References}

Bouchard TJ Jr, Loehlin JC (2001) Genes, evolution, and personality. Behav Genet 31:243-273

DeFries JC (2010) Haseman and Elston sib-pair linkage analysis: a brief historical note. Behav Genet 40:1-2

DeFries JC, Fulker DW (1985) Multiple-regression analysis of twin data. Behav Genet 15:467-473

Ferveur JF, Savarit F, O'Kane CJ, Sureau G, Greenspan RJ, Jallon JM (1997) Genetic feminization of pheromones and its behavioral consequences in Drosophila males. Science 276:1555-1558

Haseman JK, Elston RC (1972) Investigation of linkage between a quantitative trait and a marker locus. Behav Genet 2:3-19

Jallon JM (1984) A few chemical words exchanged by Drosophila during courtship and mating. Behav Genet 14:441-478

Maes HHM, Neale MC, Eaves LJ (1997) Genetic and environmental factors in relative body weight and human adiposity. Behav Genet 27:325-351

Vandenberg SG, DeFries JC (1970) Our hopes for Behavior Genetics. Behav Genet 1:1-2

Publisher's Note Springer Nature remains neutral with regard to jurisdictional claims in published maps and institutional affiliations. 